\title{
SOBRE EL TEATRO DE LUIS RIAZA. RECUERDOS CLÁSICOS EN EL DESVÁN DE LOS MACHOS Y EL SÓTANO DE LAS HEMBRAS
}

\author{
José Luis SUÁREZ GARCÍA \\ University of Texas (EI Paso)
}

SEGISMUNDO - ¡Ay, mísero de mí, y ay, infelice!

(La vida es sueño I, 2)

TI PRINS - ¡Ay, infelice de mí! ¡Ay, mísero!

(El desván de los machos...)

Cualquier clasificación del teatro de Luis Riaza siempre resulta problemática. Se ha hablado, por ejemplo, en más de una ocasión, de teatro de la crueldad, teatro del absurdo y/o del esperpento. Cierto, pero esto no es todo; como apuntara Julio Trenas, el teatro riacesco penetra en lo simbológico, transita las huellas de Antonin Artaud - bien es verdad que, en ocasiones, la crueldad se resuelve mediante un toque de humor negro-e incluso se permite el lujo de presentarnos magistralmente una resonancia clásica ${ }^{1}$.

Este marco característico del drama de este escritor contemporáneo hace comprensible que no haya sido muy positiva su acogida por su carencia de comercialidad y de comprensión. La mayoría de las obras de Luis Riaza han sido estrenadas por los grupos de teatro independientes, sobre todo en los festivales como el que se celebra en Sitges, donde en más de una ocasión se ha seleccionado una obra suya. La crítica tampoco se ha detenido con minuciosidad en el análisis de su obra. En Barcelona, por ejemplo, tras una de las representaciones en Sitges dijo que no había entendido ni una palabra. En el

1. JulioTrenas (1972) interpreta de este modo una de las representaciones de El desván de los machos y el sótano de las hembras. Creemos que este análisis es aplicable a la mayor parte del teatro de Riaza, sobre todo después de las primeras experimentaciones anteriores a 1970 basadas en la "desmitificación, por la vía del humor, de las formas dramáticas del teatro occidental contemporáneo" (Ruiz Ramón, 1986, pág. 553). 
extranjero, tal vez por estar más acostumbrado el público a la novedad, siempre peligrosa como decía Maravall, ha tenido una mejor aceptación, sobre todo por parte de críticos y estudiantes universitarios.

Estamos ante un teatro, sin duda, "difícil", adjetivo expresado por Julio Trenas tras la representación de El desván de los machos y el sótano de las hembras (1970, publicada en 1974, 1978) hecha por el Teatro Alfil en 1972. Calificativo que se puede aplicar a toda su obra en conjunto; prueba de ello es el continuo acercamiento a temas semejantes, repetición de personajes, desdoblamientos, etc. Ya el mismo Riaza apuntaba: "siempre se escribe la misma obra. Los oscuros gusanos de cada dramaturgo siempre son los mismos y siempre procura uno librarse de ellos con los mismos exorcismos"2 (Riaza, 1977, pág. 15). Y siempre se escribe la misma obra pues los problemas del hombre moderno que contempla Riaza siempre son los mismos. En este sentido la estructura profunda de sus dramas está compuesta de la observación de comunes sentimientos de alienación, enajenación, tristeza, rebeldía y, cómo no, absurdo.

Hoy queremos acercarnos al estudio de El desván de los machos y el sótano de las hembras por ser, en efecto, "una de sus obras más logradas y que, indiscutiblemente, abre [en Riaza] un período de madurez dramática" (Ruiz Pérez, 1986-87, pág. 481), con la intención de ver desde el punto de vista del lector - o, como propone Claudio Guillén, los lectores; es decir, otra forma de público- cómo Riaza presenta su forma de concebir el teatro. Toda esta "comedia" es una continua representación de elementos dobles ${ }^{3}$, desde los personajes hasta las acciones, procedentes, en su mayoría, del mundo clásico. Señalaremos ciertos elementos de la tradición que hacen que el teatro riacesco concuerde profundamente con el teatro barroco. Pero el barroquismo $-\mathrm{O}$ antibarroquismo- es paradójicamente una ironía del mismo barroquismo en el teatro. No obstante, los elementos de tradición están presentes y habrá que contar con su estudio para un mejor análisis del drama de Luis Riaza. En este momento nuestra intención es la de examinar en su temática algunos de esos aspectos de la tradición retratados de una manera muy peculiar en la mencionada obra.

Tres obras fundamentales de Luis Riaza se podrían incluir en una trilogía ${ }^{4}$ cuyo tema afín sería el poder: Retrato de dama con perrito (1976, publicada en 1977), El palacio de los monos (1977) y, finalmente, El desván de los machos y el sótano de las hembras (1970). El tema y el lenguaje están claramente

2. Para Pedro Ruiz Pérez (1986-87, pág. 480) recordando términos de la lingǘstica generativa chomskiana (en sus distintos campos de aplicación), "la dramaturgia de Riaza está conformada por una estructura profunda constante que presenta diferentes realizaciones o estructuras de superficie", en sentido de tema o subtema y no de forma o texto.

3. El mismo título de la obra es claramente significativo en su perfecta formación de parejas opuestas (desván/sótano, machos/hembras) que conlleva - como toda la obra--, no hace falta aclararlo mucho, una fuerte carga crítica.

4. Hazel Cazorla (1981, pp. 36-43) propone que dicha posible trilogía, aunque nueva, tiene sus orígenes en el esperpento de Valle-Inclán y en los poemas trágicos de García Lorca. Conviene matizar, sin embargo, que aceptando una relación con el esperpento valleinclanesco, se hace necesario separar las dos formas de concebir la realidad. Es válida la afirmación distintiva de concepción de la realidad 
interrelacionados en estos dramas; incluso se podría decir que cada uno representa un espejo del otro. El tema del poder es, no obstante, el nexo de unión más claro. No se analiza exclusivamente el poder político sino todos los tipos de abusos a los que el ser humano se ve sometido por parte de la autoridad. Estamos, pues, ante un tema clásico y moderno. El autor maneja "irónicamente" el tema desde perspectivas casi barrocas, pero el trasfondo inyecta a la obra una dosis de modernidad y, así se critica mediante la forma — donde reside la posible revolución teatral- $y$, a veces, el contenido, las violaciones de las dictadura individuales y las colectivas.

El lenguaje es también otro nexo de unión de estas obras. Ya incidimos en las opiniones del autor, quien mantenía que siempre se escribe la misma obra. Siendo cierto que siempre se escribe la misma obra, no es extraño que el lenguaje sea correlativo. Pero Riaza al elegir su lengua no se limita a la búsqueda de un lenguaje análogo y solidario, sino a la ruptura del propio lenguaje, a la no fijación de normas en la forma. Esto representa, a la vez, en Riaza, una crítica a la fijación de normas en el contenido. Este lenguaje, o metalenguaje, servirá de base para la desintegración del teatro y surgirá, como la reproducción del poder por "autofecundación", un nuevo teatro que a la vez habrá que destruir nuevamente para su reaparición como forma de teatro y teatro de teatro, es decir de metateatro.

En El desván de los machos y el sótano de las hembras Luis Riaza, decidido a crear un teatro "en el que, aparte del mensaje, del discurso verbal, hay también una propuesta de imágenes y de incitaciones a la plástica y a otras artes" (Ramos, 1982, pág. 19) y consciente de la dificultad del lector en comprender la obra ${ }^{5}$, presenta un "prólogo". Dicho prólogo habla del teatro de

expuesta por Pedro Ruiz Pérez (1986-87, pág. 486): "Valle pasea a sus personajes delante de sus esperpéticos espejos para comprobar la nueva imagen que éstos reflejan. Convirtiéndolo en un proceso de indagación epistemológica, Riaza, por el contrario, lo hace para analizar y mostrar los mecanismos de deformación a que estos espejos someten la realidad". A esta influencia, sobre todo, valleinclanesca, y algunos posibles reflejos lorquianos, hay que añadirle otro trasfondo histórico: la tradición barroca (de la que, por cierto se valen Valle-Inclán y Lorca). Recordemos, sin profundizar en múltiples ejemplos, desde el propio Renacimiento el inicio de una fuerte tensión, violencia y en ocasiones deformación que se manifestará claramente en el Manierismo y culminará en el Barroco, y que afectó no sólo a la literatura, sino prácticamente a todas las artes. Por otra parte, el mismo autor, en la introducción de El desván de los machos y el sótano de las hembras (1978, pág. 24) comenta la división de su teatro en dos grupos: por un lado, obras "de carácter espectacular, teatroscópicas, corales, una especie de friso general de la sociedad, tales como El palacio de los monos y Los huevos de la moscarda"; por otro, "otras, de relaciones más intimistas, no psicológicas, pero sí de lucha, de situaciones personales, como Retrato de dama con. perrito y El desván de los machos y el sótano de las hembras". Esta afirmación, en principio destruye nuestra pretendida agrupación en trilogía. Sin embargo, creemos que ambas clasificaciones son perfectamente compatibles.

5. La obra tiene diferentes dimensiones desde el punto de vista del lector y del espectador. Este comentario, en principio obvio, y aplicable a prácticamente todo obra teatral se hace más notable en este singular drama en el que su autor intercambia papeles y acciones violentamente y por tanto el estado de confusión es más profundo en el lector que en el espectador. Pero a la vez el espectador no percibe elementos de ruptura del lenguaje presentes en el texto $y$, a veces, ausentes en la representación.

6. La función de este prólogo de Luis Riaza es general un tratado teórico de su concepción del drama. La forma utilizada se acerca, en parte, a los escritos vanguardistas de fijación de ideas. También 
Riaza para que no nos salgamos del texto, aunque, a su vez, incita a la múltiple interpretación del texto ${ }^{7}$. Se aclaran las pretendidas dimensiones del dramaturgo, se exponen los ideales de un teatro nuevo, cómo ha de ser y qué ha de representar. En este prólogo ya se dan los primeros indicios de los elementos que aparecerán en el texto dramático. Seguidamente se da paso a la "Síntesis crítico-argumental" donde aparecen resumidos los elementos fundamentales de la trama. En seguida se introduce al primer personaje-actante ${ }^{8}$, DON, que aparece bajo el calificativo de "señor". El siguiente personaje es BONI, quien es su "servidor" y a la vez su doble/contrario. En este primer acercamiento al texto se nos sitúa también espacio-temporalmente. La acción se desarrolla en "un extraño castillo", donde se está celebrando una "ceremonia". Es decir, estamos ya inmersos en el teatro dentro del teatro.

DON representará el poder y el control durante toda la obra. Este personaje, reflejo de los grandes terratenientes de la antigüedad, vive en su mansión/ castillo aislado del mundo pero con el control absoluto. Es también un representante directo del dictador común que se vale de su poder para complacer su ánimo, su aburrimiento, su crueldad. Y el bufón, su doble, su cómplice, es un ser más de los representantes de la marginación, y aunque haga en ocasiones de DON, sabemos, y él sabe, que nunca tiene ni tendrá poder ${ }^{9}$, aunque en apariencia y como producto de una acción carnavalesca la inversión del rol resulte comprensible y aceptable ${ }^{10}$. Éste es, pues, el primer desdoblamiento llamativo,

recuerda (a pesar de la ironía del prólogo, y prólogo del prólogo) en forma y contenido a las preceptivas del Siglo de Oro. Y no menos importante es ese breve "tratadito" de Lope de Vega, Arte nuevo de hacer comedias (publicado en 1609 , peroescrito probablemente en 1606) donde la ironía hace acto de presencia para exponer los preceptos del nuevo teatro "revolucionario" para su entonces, que habría de triunfar. También en este prólogo de Luis Riaza se encuentra un recuerdo de lo que se ha llegado a considerar un género literario en el Siglo de Oro. Seguidamente al prólogo se encuentra la "Síntesis crítico-argumental" tan frecuente en todo tipo de obras dramáticas de nuestros clásicos.

7. En los dramas de Luis Riaza texto y espectáculo están concebidos para que el lector o espectador sean elementos participantes de la acción. Señala el mismo Riaza: "Mi forma de entender el teatro corre paralela a toda una forma de comprender la literatura contemporánea por cuanto es una obra abierta, y es justamente la co-creació del espectador la que tiene que dar su último sentido. Intento hacer una obra en la que el espectador pueda tener su propia creación" (Ramos, 1982, pág. 19).

8. Anne Ubersfeld en Lire le théâtre (1978) afirma que: 1) un actante puede ser una abstracción, o un personaje colectivo o una reunión de varios personajes; 2 ) un personaje puede asumir simultáneamente situaciones actanciales distintas; y 3) un actante puede estar escénicamente ausente, y su presencia textual no inscribirse más que en el discurso de los distintos personajes. Para mayor detalle sobre el tema véase Jorge Urrutia (1985, pp. 87-95). DON y BONI tienen alguna cualidad de actantes, por su abstracción como tipos; a la vez en su intercambio de roles. Riaza en otras ocasiones utilizará un desdoblamiento para que, como él mismo comentara, un mismo personaje adquiera una doble o triple personalidad.

9. Comenta Maravall (1990, pp. 134-135) respecto a la situación de ociosidad del señor y su relación con el criado: "De ahí que, necesariamente, según la naturaleza de la sociedad ociosa, en la Europa de los siglos XVI y XVIII, y más acentuadamente en España, el señor tenga que permanecer ocioso y haya de tener a su alrededor una legión de criados para las más inverosímiles atenciones".

10. Escribe Alfredo Hermenegildo (1991, pág. 30) al respecto: "Si los interlocutores son amo y criado, galán y gracioso, la orden sale casi indefectiblemente de boca del primero; su ejecución es obra del segundo. En general esta función ejecutora marca la dependencia jerárquica de los espacios de señores y criados y, al mismo tiempo, la incapacidad de realización, de ejecución, que el señor tiene. A través de esta función el criado actúa como manos, brazos y pies del poderoso. Y confirma al mismo tiempo la dependencia a que el amo está reducido. A menos que el carácter bufonesco del gracioso le permita la 
DON/BONI. En una ocasión respondiendo Riaza a la pregunta de si le obsesionaban las ambivalencias sexuales comentaba: "Sí me interesa que escénicamente un actor no sea el signo unívoco de un solo personaje. Un actor puede representar al mismo tiempo dos personajes. La explicación más válida de esto puede ser el intento mío de renovar formas"'. (García Pintado, 1974, pág. 8).

Otros elementos dobles aparecen en toda la obra, pero es sin duda éste el que más llama la atención por la irónica inversión -en ocasiones, confusiónde mundos que produce. En todo el teatro del Siglo de Oro se observa también esta inversión de roles, sobre todo entre el galán y el criado o gracioso. Comenta Alfredo Hermenegildo (1991, pág. 29) sobre dicha relación:

Hemos utilizado como modelo experimetal de análisis la comedia española del Siglo de Oro, en la que el juego de personajes queda reducido con frecuencia a unas parejas repetidas $y$, en consecuencia, dotadas de unas funciones recurrentes. Una de esas parejas en las que constituyen el galán y el gracioso, pareja que vive escénicamente en relación especular, imitativa, u opuesta dialécticamente. La práctica dramática de la época prevee una doble manera de insertar al criado en el espacio dramático. La que caracteriza al servidor, como doblete del señor e instrumento útil para la realización de sus decisiones, y la que configura la figura del gracioso.

Y son numerosos los ejemplo de señores que obligan a sus criados que les hablen y actúen según sus deseos ${ }^{12}$. Pero Riaza crea un modelo diferente de interteatralidad intertextual más reconocible en este caso por el espectador que por el lector.

Ésta es, sin duda, la primera introducción al abuso del poder. Todo ello en medio de una gran ceremonia. Se vale precisamente de la ceremonia, que fuera en su momento el inicio del teatro ${ }^{13}$. Y es precisamente la ceremonia religiosa

asunción carnavalesca de la función actoral del señor, en cuyo caso bien puede imperar y hacer que el otro ejecute la orden asumiendo provisional y carnavalescamente la función actoral de criado". Véase también Alfredo Hermenegildo, "El gracioso y la mutación del rol dramático: Un bobo hace ciento, de Antonio Solís" (1989, pp. 503-526).

11. En Retrato de dama con perrito encontramos al personaje doble Gran Dama/Benito. Incluso llega a utilizar un triple personaje, Mayordomo/Cocinero/Portero Mayor en El Palacio de los monos.

12. Los ejemplos de este tipo de abuso de la autoridad de los criados son innumerables. Uno más tempranos y conocidos es el de Calisto que desde el comienzo de La Celestina (1987, pp. 95-96) y atacado por la locura de amor y lleno de soberbia arremete verbalmente contra su criado Sempronio, que aunque se burle de su ano, le sigue en el juego. Su destino final será la muerte.

CALISTO. ¡Maldito seas! Que hecho me has reyr, lo que no pensé ogaño.

SEMPRONIO. ¿Pues qué? Toda tu vida avías de llorar?

CALISTO. Sí.

SEMPRONIO. ¿Por qué?

CALISTO. Porque amo a aquella ante quien tan indigno me hallo, que no la espero alcançar.

SEMPRONIO. (¡O pusillánime, o fi de puta! ;Qué Nembrot, que magno Alexandre; los cuales no sólo del señorío del mundo, más del cielo se juzgaron ser dignos!

CALISTO. No te oy bien esso que dixiste. Toma, dilo, no procedas.

SEMPRONIO. Dixe que tú, que tienes más coraçon que Nembrot ni Alexandre...

13. El mismo Riaza en la entrevista que le hizo Angel García Pintado (1974, pág. 11 ) había señalado: "Estimo que el teatro ceremonial puede atacar más la conciencia del espectador burgués". Algunos puntos sobre el aspecto ceremonial en la dramaturgia de Luis Riaza los desarrolla Peter L. Podol (1982). 
la que adquiere mayor valor por ser la que está más en contacto con la divinidad, y por tanto, la realidad riacesca. Toma así valor la afirmación del propio autor: "Porque, a lo mejor/peor, el teatro se ha quedado en eso, en misa [...], en refugio de la poca religiosidad extraeclesial [...] que en el mundo va quedando" (Riaza, 1981, pág. 8). Aunque Riaza gusta de los ceremoniales en sus obras y su teatro es un teatro de ceremonia - e insiste repetidamente en la ceremonia religiosa-- se trata, a su vez, un "ataque a la artificialidad de la ceremonia" que tiene como objetivo la "denuncia y anulación de la efectividad que los propios mecanismo de alienación tienen sobre el individuo receptor" (Ruiz Pérez, 1986-87, pág. 490-491).

Seguidamente se introduce un tema polémico, la procreación que este ser hace de sí mismo. Reproducción por autofecundación que plantea un problema moral-religioso. Él es el principio y el fin. No hay tiempo presente, pasado y futuro sino que todo es atemporal. Este hecho, que no resulta muy incomprensible pues estamos en el teatro, no lo olvidemos, entra dentro de planteamientos puramente filosóficos sobre el origen/principio y el fin del hombre. Pero a la vez en medio de esta irónica procreación individual se encuentra parte de la base unitiva del pensamiento del autor sobre el teatro. Éste, aunque se destruya, y es necesario destruirlo porque sus mecanismos denunciadores no tienen efecto inmediato y se hace necesaria una nueva forma de instrucción, se procreará y así la muerte del teatro es su resurgimiento inmediato.

Todo está escrito en un libro (intertextualidad), bien inexistente, bien en blanco. Este libro del que se dice que "fija la metahistoria pasada, presente y futura" es, además de otros valores, una ironía de los antiguos libros de crónicas, cuya esencia era fijar hechos históricos en el sentido intrínseco del término, es decir, reales. Recordemos los libros de crónicas medievales, las crónicas de la conquista del Nuevo Mundo y la importancia de la historiografía en el Renacimiento y Barroco, con una gran preocupación por rehacer la veracidad de la historia. El libro toma aquí carácter pleno de símbolo ${ }^{14}$. En primer lugar por ser libro, material de intrucción (o denuncia) que aunque físicamente no aparezca en su integridad se conoce y acepta la existencia de su contenido. En segundo término porque el libro en blanco (como lo era en latín para el vulgo) es ininteligible para el ser alienado que colabora voluntaria o involuntariamente con la crueldad del alienador.

Pero el libro tiene dos "fisuras". Seguimos con los elementos dobles. Una exterior: la leprosería, los habitantes del exterior, quienes "pueden constituir una excepción, una libertad, que se filtre y venga a corroer las estructuras internas" (Riaza, 1978, pág. 128), donde emerge el universal tema de la posibilidad de sublevación de la masa. Ellos, quienes se sienten protegidos por el señor "feudal" y que no creen en la posibilidad de ascender socialmente (ni

14. Sobre la escenificación de símbolos Riaza comenta "más que símbolos son situaciones. Para mí es más importante la sugerencia que la anécdota. Su esencia es la ambigüedad". (Ramos, 1982, pág. 20). 
siquiera se plantean el problema), son una amenaza. DON sí sabe que existe la posibilidad de mover dicha masa y que, por otra parte, es fácilmente vulnerable ${ }^{15}$.

De otro lado tenemos una amenaza interior, y a pesar de los controles manejados por el poder existe una "profecía" escrita en este libro irónico, llena de veracidad. Es la posibilidad de la pérdida del poder desde el interior. La carne que le sucederá no es únicamente el paso heriditario del poder sino, a su vez, la representación de la posibilidad de sublevación interior, la del hijo ${ }^{16}$, que se produce pero que ha sido prevista por DON y es fácilmente controlada. En el seno de esta profecía está todo el enjambre de las supersticiones y creencias de la antigüedad en el mundo de los astros. Sin embargo, en el caso que hoy nos ocupa, tenemos el recuerdo de Calderón, quien en La vida es sueño pone a un rey, Basilio, que se dedica a la astrología ${ }^{17}$. Los astros han previsto que el hijo no gobernará prudentemente y por eso se le trata desde su nacimiento como un animal - a pesar de ser instruido en las artes y las ciencias- y su padre, el rey y representante del poder absoluto, lo aparta del mundo.

Aparece, en este momento, el tercer personaje de la obra: TI PRINS o PTI PRINS (pronunciación acelerada de Petit Prince). En efecto, estamos, como el mismo Riaza señala, ante un universal "pequeño-príncipe, pequeño segismundo". Se trata de un personaje sumergido en la alienación. La alusión al clasicismo no

15. Creemos se está haciendo referencia a todo tipo de revoluciones ideológicas (que conlleva, a su vez, una revolución teatral misma) y sociales; sobre todo las modernas, tanto reales como las ideules propuestas por los diferentes filósofos y grupos de vanguardia. Pero no menos significativo es el hecho de que ya desde la tradición se haya mencionado la fuerza de presión del vulgo, como peligro para la alteración del orden establecido. Cervantes en el prólogo de Quijote I ya presenta su preocupación por la reacción del pueblo ante su libro: “cómo queréis vos que no me tenga confuso el qué dirá el antiguo legislador que llaman vulgo...?" Lope de Vega escribe en Amar sin saber a quien: "Diciendo el vulgo en voz alta/que era el que mató a don Pedro" y en Amigo hasta la muerte: "Es el vulgo desigual/con razón le tenéis temor". En los dramas de comendadores, el pueblo se subleva e incluso mata al tirano y señor. También Calderón se acordará del vulgo. En Ni amor se libra de amor escribe: "¿Quién a un vulgo desbocado/determinado y resuelto/a raya podrá parar" y en La vida es sueño encontramos "vulgo, soberbio y atrevido". Finalmente queremos apuntar que esta idea de alzamiento del vulgo no es exclusivamente española; en Hamlet, por ejemplo, se menciona en tres ocasiones al pueblo sedicioso y se le llama "lawless resolutes" (I, 1, pág. 98); "He's loved of the distracted multitude" (IV, 3, pág. 4); "The rabble call him lord" (IV, 5, pág. 101). Para más detalles véase Porqueras Mayo (1972, pp. 114-127).

16. En las obras cuyo tema base es el poder es común la aparición de un personaje que será heredero del poder. En la trilogía mencionada tenemos: Para El desván, y El Palacio de los monos, Ti Prins; Retrato de Dama con Perrito, Artista Adolescente. Y de otras dos obras donde el tema del poder adquiere un valor significativo: Drama de la dama que lava entre blancas llamas, Señorito; y en Los perros, Pequeño Rey. La sublevación es producida por la hija, pero si tenemos en cuenta que toda la obra representa un juego de intercambio de roles, la idea —expuesta por humanistas italianos y españoles, sobre todo, desde el Renacimiento-- de que es el heredero el que se alza contra el poder puede ser aceptada y entendida aquí en su contenido y no en su forma.

17. Para Calderón y su público un rey científico es un rey absurdo. Sin embargo sabemos que Basilio sí creía en el poder de la determinación de los astros. También es muy frecuente en toda la literatura clásica, sobre todo en el Renacimiento, tras los avances de ciencias como la astronomía y la astrología, encontrar ejemplos del determinismo que se tenía ante el cosmos. Para no entrar más en detalles queremos mencionar los estudios de Pedro Ciruelo (1978), Antonio Hurtado Torres (1984) y Mario N. Pavia (1959). No olvidemos otras obras como la de Calderón El astrólogo fingido y de Alfonso X "el Sabio", Libro de las cruzes. 
puede ser más clara ${ }^{18}$. Frente al problema que planteara, sobre todo, Maquiavelo acerca del origen, naturaleza y función del príncipe ${ }^{19}$ en la cual éste pudiera no continuar la estirpe en casos determinados, Riaza presenta un "señor" que no deja paso a la sucesión del trono. No hay lugar para contemplar el posible "maluso" del poder según lo establecido por DON. Según esto, tenemos un hijo "natural" al que "descualifica" y presenta como un ser deformado mentalmente, carente, por tanto, de las cualidades inmanentes de un verdadero príncipe preparado para asumir el control absoluto. Un príncipe que no sólo no distingue su propia identidad, sino que ante la autoridad reacciona sin sentido común:

DON. (Intenta retirarse. TI PRINS se lo impide, abrazándole). ¿Qué pretende este hijo pobre hijo mío? ¡Menester será acortar aún más los fierros a su extraño desvario...!

TI PRINS. (A BONI) Señor padre.

18. Ya desde la época medieval eran comunes los tratados o espejos de príncipes (speculum principis), sobre todo a partir de finales de siglo XV por las circunstancias políticas entre las que cabría destacar la subida de los poderes monárquicos y las transformaciones de intelectuales en cortesanos. hacia 1480 Diomene Carrafa publica De regis et boni principis officio; hacia 1481 Platina, De vero príncipe; hacia I 494 Francesco Patrizi, De regno et regis institutione; alrededor de 1503 Pontano, De principe liber. En España los tratados sobre príncipes que destacaron fueron los de Rivadeneira (1595) contra Maquiavelo y Mariana (1599) quien aceptará el tiranicidio. La obra maestra de estos tratados es, no obstante, // Principe (De principatibus, 1513) de N. Maquiavelo de la que queda un cierto recuerdo en Riaza en El desván... y en otras obras como en El Fernando (1971). Con este primer origen y otras resonancias más tardías referentes a otros "príncipes" hace Riaza una refundición de su nuevo personaje.

19. Maquiavelo insiste, entre otros puntos, en los primeros capítulo de $/$ Principie en la división de los principados en hereditarios y mixtos (ereditarii o nuovi). En los principados hereditarios son menores las dificultades de su conservación.

Dico, adunque, che nelli stati ereditarii et assueffati al sangue del loro principe, sono assai minori difficultà a mantenerli che ne' nuovi, perché basta solo non preterite l'ordine de' sua antinati, e poi temporaggiare con li accidenti... (De principatibus hereditariis).

Éste se mantendrá en su poder, establecido por los predecesores. Existe la posiblidad de lo que pierda en un acontecimiento inesperado pero lo recobrará en el primer descuido del "usurpador".

... se tale principe è di ordinaria industria, sempre si manterrà nel sou stato, se non é una estraordinaria et eccesiva forza che lo privi; e, privato che ne fia, quantenque di sinistro abbi l'occupatores, lo riacquista. (De principatibus heridiatariis) (Machiavelli, 1963, pág. 6).

En los principados mixtos (De principatibus mixtis) existe la posibilidad de rebelión contra el gobernante. Luis Riaza en el "prólogo" de El desván (Riaza, 1978, pág. 57) apunta lá posibilidad de que el príncipe se subleve:

\section{TEORÍA DEL PRINCIPITO TRAIDOR}

(subcapitúnculo en el que se trata de cómo el hijo de papá puede mediar entre el apestado (de próxima aparición

y la guillotina

que solamente de los cuervecitos criados por

papá y a leche bendita de papá cabe esperar el

reventado de ojos de papá

porque de ellos es el inicio de la revolución 
BONI. Llámame papá.

TI PRINS. (...) Señor papá: ¿por qué... ${ }^{20}$ (Riaza, 1978, pág. 146)

He aquí una posible referencia a los clásicos tratados de príncipes que se amplía en el entramado escénico de la propia ceremonia. Es como indica Alberto Castilla (1978, pág. 24. Prólogo a la edición de El desván...) un "Maquiavelismo de un laberinto de ceremonias en el que anda atrapado el hijo de tal señor feudal a base de que le van cultivando un feroz machismo de alimaña salvaje". No obstante, la referencia más clara de Ti Prins en El desván de los machos y el sótano de las hembras, parece ser la ya mencionada obra de Calderón, La vida es sueño ${ }^{21}$. En ella desde el principio encontramos a un príncipe privado de la libertad por su padre y señor. En Calderón por miedo a que no gobierne prudentemente, según las estrellas. En Riaza se utiliza la "profecía" para la negación inmediata y el miedo a la sucesión. En Calderón se hace comprensible, hasta cierto punto, la actitud del rey que se enfrenta a la dualidad de padre que encierra a su hijo y gobernante que ha de buscar el bien del pueblo e intentar protegerlo del mal. En Riaza dicha actitud no es posible y por tanto se vale no sólo de la crueldad de encadenarlo, sino que además lo presenta como deformado mentalmente. Así la escena toma características aún más esperpénticas.

Además de este recuerdo clásico se encuentra en este personaje la huella de otro clásico príncipe. Se trata de la obra de Antoine de Saint-Exupéry Le Petit Prince. En primer lugar hay elementos de esta obra que aparecen en El desván, así como otros referidos a su pensamiento, reflejado en otras obras. No cabe duda en la relación, coincidencia premeditada, de TI PRINS con el pequeño príncipe, en cuanto a los nombres. Además, el pequeño príncipe de SaintExupéry visita a un rey en su primer planeta donde se exponen ideas que nos hacen pensar en un rey sabio y justo (Comme il était très bon, il donnait des ordres raisonnables). Sin embargo, en otros términos se presentan los ámbitos de poder del rey, quien tenía el poder absoluto, a pesar de su buen uso.

C'etait un monarque absolu.

Elles obéissent aussitôt [les étoiles]. Je ne tolère pas I'indiscipline.

Il avait un gran air d'autorité (Saint-Exupéry, 1943, pág. 38).

20. Además de esta incapacidad de distinguir un silogismo elemental tenemos las constantes referencias en las que se le manda ir a su "rincón" y se la trata siempre como un alimañá. En algunas ocasiones se utiliza un tono paternalista que da un toque irónico a la maldad de DON (Lucero, hijo mío, mi niño...). Pero pronto el fíngido paternalismo desaparece y se da paso a la crueldad. pág. 48).

DON... ¡Húndete de una vez en tu cueva o terminaré por olvidarme de quien eres! (Riaza, 1978.

21. La bibliografía de Segismundo es amplia, sobre todo desde el antiguo estudio de Enrique Fuines (1899). Es importante para nuestro tema la tesis doctoral de Richard Whiteley Norton (1960) donde además de un profundo estudio del personaje de Segismundo desde una doble perspectiva (por una parte en término teológicos, molinista/tomista; por otra, desde el punto de vista de la no cristiandad [enfoque en las doctrinas estoicas]) se presenta una interesante bibliografía. También puede consultarse (entre otros motivos por ser más reciente y abarcar otros campos que la bibliografía de Norton) la que Ciriaco Morón presenta en su edición de La vida es sueño (1986). 
También se exponen ideas de los principios que incitan a las revoluciones. Dichos principios están motivados fundamentalmente en el abuso del poder y la autoridad:

L'autorité repose d'abord sur la raison. Si tu ordonnes à ton peuple d'aller se jeter a la mer, il fera la révolution.

Autoridad a la que DON no se atiende y en su crueldad no contempla ni a su hijo ni a su gente. A pesar de todo, vive con el temor a la revolución interior y exterior, y a la muerte; su muerte como la de los "comendadores" o reyes injustos de la antigüedad, o como la del dictador común, siempre en tensión por temor al golpe militar. Además de las ideas sobre la libertad que se presentan en Le Petit Prince aparecen en Riaza reflejos del mundo que contempla SaintExupéry en otros escritos suyos. En Citadelle expone otros pensamientos referentes al creador y a lo creado. De este último concepto escribe:

... toute création d'abord est cruelle (Saint-Exupéry, 1948, pág. 109).

... la création est d'une autre essence que l'objet creé qu'elle domine... (Saint-Exupéry, 1948, pág. 213).

El creador (DON) posee el poder de la cosa creada (TI PRINS); es su esencia y su dominante. Mediante un ritual/ceremonial lleno de crueldad se representa la marginación y la depravación de los seres humanos, sobre todo los "machos" (de las hembras ni se hable, pues no hay espacio para ellas ni siquiera en la concepción):

DON. Y padre, como no sabía, después de todo, cómo proseguir, vino a plantar un árbol.

BONI. ¿Un granado? ¿O se trataba, quizás, de una higuera?

DON. Me permito recordar al señor que ciertos árboles femíneos soñarían en estas alturas como puras blasfemias. Forzoso es que se tratara de un árbol macho.

BONI. ¿Pongamos un olivo?

DON. $\quad$ Pongamos (Riaza, 1978, pág. 136).

Finalmente conviene analizar otro elemento - a la vez desdoblamientodel drama riacesco y que afecta a la estructura y contenido de la obra que hoy analizamos: el tratamiento y presentación de una posible tragedia/comedia. ¿Estamos ante una tragedia o una comedia?

¿Cómo evitar que dicho destino tenga su fatal cumplimiento? ¿Cómo conseguir que la comedia de la perduración no degenere en la tragedia de la consunción? (Riaza, 1978, pág. 128).

Si nos atenemos al contenido vemos que Riaza presenta, en principio, más bien una comedia que una tragedia.

Así se le presentarán al tercer personaje que ahora surge de debajo del lecho fundacional, que emerge a la comedia desde su oscura caverna de la alienación (Riaza, 1978, pág. 129). 
Mañana pariremos otra hembrita que venga a hacer posible la continuidad de la comedia (Riaza, 1978, pág. 132).

En otra ocasión parece no definir ningún modelo, ningún género específico que limite de alguna forma al teatro, del que incluso duda como tal, a modo cartesiano:

nuestra justificación y nuestra defensa de cuando vivíamos pasa a incidir sobre el origen de la cosa y del teatro (o lo que sea que pretendemos prologar y el origen de esta tragedia (o lo que sea estriba, muy probablemente, en que el pobre tipo que la compuso era un goloso de realidad al que siempre le era negada la realidad (Riaza, 1978, pág. 44).

Riaza en su teatro no se conforma con las limitaciones impuestas por los géneros literarios. Sin embargo, no cabe duda que de un modo u otro participa de dichas limitaciones. En este planteamiento entre lo cómico y lo trágico, entre la tragedia y la comedia reside parte del barroquismo de Riaza:

Teatro decididamente barroco, no por restaurar elementos ideológicos y ornamentales ya difuntos, sino, sobre todo, por la presencia de una serie de factores muy sabiamente conjugados: la fusión de lo trágico y lo cómico, uso repetido de técnicas de teatralidad, de ceremonia, de teatro dentro del teatro; pompa y solemnidad, convenientemente degradadas por la introducción de elementos de ruptura (Alberto Castilla. Prólogo Riaza, 1978, pág. 28).

Aparecen, pues, elementos tanto de la tragedia como de la comedia. Para aclarar o responder a la pregunta que planteábamos sobre la existencia de comedia o tragedia conviene analizar algunos elementos de genología. Según Aristóteles la tragedia debe despertar compasión y emoción violenta, pero deleitable, en el espectador (VI, 1499b, 24-28). Muchas de las ideas aristotélicas pasaron a la escolástica, que aceptó o modificó los principios establecidos por el Estagirita en función de nuevos preceptos. Anteriormente, pues, a la vuelta del Renacimiento al mundo clásico existía una clara definición de lo que debiera ser y contener la tragedia y la comedia ${ }^{22}$. Posteriormente, el Pinciano, entre otros preceptistas, resume los comentarios de algunas autoridades de la antiguiedad así como de Evancio-Donato, que se ha denominado teoría tradicional ${ }^{23}$. Tras la multiplicidad de distinciones que se aplicaban a la comedia y la tragedia el Pinciano las acortó

22. Dicha teoría se encuentra en los comentarios de Capurnio, Juvernal, José Badio Ascensio, Benito Filólogo, Victor Fausto (segunda mitad del siglo XV). Se comentan las comedias de Terencio y Séneca.

23. Los puntos fundamentales de dicha teoría tradicional expuesta por Alonso López Pinciano en su Philosophía Antigua Poética (1595) han sido recogidos por Margarete Newels (1974, pág. 71):

1) La tragedia ha de tener personas graves [o sea, de elevado rango], y la comedia, comunes [o sea, de origen humilde y de características típicas más bien que individuales].

2) La tragedia tiene grandes temores llenos de peligro, y la comedia, no.

3) La tragedia tiene triste y lamentables fines; la comedia, no.

4) En la tragedia, quietos principios y turbados fines; la comedia, al contrario.

5) En la tragedia se enseña la vida que se debe huyr; y en la comedia, la que se debe seguir.

6) La tragedia se funda en la historia; y la comedia, es toda fábula, de manera cue ni aun el nombre es lícito poner de persona alguna.

7) La tragedia quiere y demanda estilo alto; y la comedia, baxo. 
en un motivo fundamental: la risa. Partirá del pasaje V (1449 a, 31-36) de la Poética de Aristóteles, aunque su fuente directa esté más bien en el Tractatus Coislinianus. Juan de la Cueva (siguiendo al Pinciano) señala en su Ejemplar poético: "La Comedia es retrato del Gracioso/ y risueño Demócrito, y figura/La Tragedia de Eráclito Iloroso" (Juan de la Cueva, 1953, pág. 166). Esta definición mucho más simple no necesariamente vino a delimitar con claridad los géneros. Lo que sí es claro es que tras el triunfo de Lope y su teatro se denominó "comedia" a prácticamente todas las obras con independencia de su contenido y finalidad (véase, por ejemplo, cómo al final/principio de las obras así se las llamaba). De dicha controversia teatral aparece un nuevo término que vendría, en parte, a aclarar la cuestión. Entra en juego la "tragicomedia"24. Nuevamente los preceptistas comienzan sus disputas en torno a la tragicomedia. Encontramos obras que en principio pertenecen a la comedia pero su final es calamitoso, como es el caso de La Celestina $^{25}$. Dichas obras por su temática y contenido entran dentro de ambos géneros.

Según esta confusión de términos existente desde la Antiguiedad no es extraño que Riaza en su visión teatral no se defina dentro de un grupo. Ahí reside parte de su labor creadora, que se basa en la burla e ironía del mismo teatro barroco al que hacemos referencia. Se trata de un teatro que, a pesar de lo trágico y cómico, pretende ir más allá de ambos términos. Una obra que se sale de la antigua comedia, la tragedia y la tragicomedia. $Y$ en su salida de toda imposición restrictiva se desarrollan elementos que de lo cómico pasan a lo burlesco y grotesco. Lo trágico no llega a ser trágico sino que entra en lo violento de una crueldad cuidadosamente premeditada.

Vemos con claridad que Luis Riaza desmonta magistralmente los cimientos del teatro clásico para crear una nueva forma escénica basada en la irónica representación del teatro mismo. Éste es un medio de información y denuncia, encubierto por lo absurdo del hombre presente/actual (como público) que tiene la función de desenmascarar los secretos de una fuerte crítica social. Esos personajes/tipos y ese teatro a los que nos hemos referido ${ }^{26}$, (basándonos, sobre todo, en El desván de los machos y el sótano de las hembras) están cargados de clasicismo anticlásico y revolucionario. Riaza escribe sobre lo habitual en la escena española, de manera aparente, pues en realidad es "contra lo habitual en

También en este estudio M. Newels analiza los principios fundamentales establecidos por las otras dos poéticas más importantes de la época: El cisne de Apolo (1602) de Luis Alfonso de Carvallo y Las tablas poéticas (1617) de Francisco Cascales.

24. Marcelino Menéndez. Pelayo explica con claridad dicha polémica en el capítulo X de su Historia delas ideas estéticas. Hemos de mencionar para nuestro propósito que el término "tragicomedia" no tenía el mismo significado en Italia, Francia y España. En Francia e Italia era un género más, mientras en España intentaba definir el nuevo teatro.

25. La Celestina, recordemos, apareció en un principio bajo el título de comedia y sucesivamente bajo el de tragiconedia.

26. En nuestro trabajo no hemos mencionado el papel de LEIDL. Aunque es fundamental, al ser el segundo elemento el par TI PINS/LEIDI, y encarnar figurativamente, la representación del elemento femenino - a pesar de los desdoblamientos producidos por los machos en hembras - con posibilidad, pero no necesidad, de procreación; su análisis completo saldría de nuestro propósitos de búsqueda de algunas huellas clásicas que configuren la obra textual de Luis Riaza. Dejamos para otro momento el peligroso y largo análisis del personaje femenino en la dramaturgia riacesca. 
la escena española" (Ruiz Pérez,1986-87, pág. 494). La dramaturgia de Luis Riaza, una de las más fascinantes formas del teatro contemporáneo, tiene escondido un mundo subterráneo de singular contemplación del hombre moderno.

\section{OBRAS CITADAS}

ARISTÓTELES. 1974. Poética, Ed. trilingüe, ed. Valentín García Yebra, Madrid, Gredos.

CALDERÓN DE LA BARCA, Pedro. 1986. La vida es sueño, ed. Ciriaco Morón, 13" ed., Madrid, Cátedra.

CAZORLA, Hazel. 1981. "The Duality of Power in the Theater of Luis Riaza", Modern Drama, 24-1, pp. 36-43.

CIRUELO, Pedro. 1978. Reprobación de las supersticiones y hechicerias, ed. Alva V, Ebersole, Valencia, Albatros-Hispanófila.

CUEVA, Juan de la. 1959. Ejemplar poético, Madrid, Clásicos Castellanos.

FUNES, Enrique. 1899. Segismundo: Estudio crítico, Madrid, Victoriano Suárez.

GARCÍA PINTADO, Angel. 1974. "El Dante-Riaza: entre el más allá y el más acá", Primer Acto, 172, pp. 8-11.

HERMENEGILDO, Alfredo. 1989. "El gracioso y la mutación del rol dramático: Un bobo hace ciento, de Antonio Solís", Diálogos Hispánicos de Amsterdam, Atlanta (Georgia, USA), Rodopi, vol. 8, nำ (Dramaturgos y géneros de las postrimerías), pp. 503526.

- 1991. "La ponderación del personaje teatral: Proposiciones metodológicas",Texto y Espectáculo. Nuevas aproximaciones críticas a la Comedia, Ponencias del XI Simposio Internacional de teatro del Siglo de Oro, Texto y Espectáculo, celebrado en Ciudad Juarez en Marzo de 1990, El Paso, Texas, Unniversidad de Texas, El Paso, pp. 25-38.

HURTADO TORRES, Antonio. 1984. La Astrología en la literatura del Siglo de Oro, Alicante, Instituto de Estudios Alicantinos.

MACHIAVELLI, Niccolò. 1961. Il Principe, Introducción y notas Federico Chabod, ed. Luigi Firpo, Torino, Giulio Einaudi.

MARAVALL, José Antonio. 1990. Teatro y literatura en la sociedad barroca, ed. corregida y aumentada, Barcelona, Crítica.

NEWELS, Margarete. 1974. Los Géneros Dramáticos en las Poéticas del Siglo de Oro, Versión española de Amadeo Solé-Leris, London, Tamesis.

NORTON, Richard W. 1960. "Casuality in Calderon's La vida es sueño", Tesis doctoral, Urbana, Univ. Illinois.

PAVIA, Mario N. 1959. Drama of the Siglo de Oro: A study of the magic, Witchcraft, and other occult befliefs, New York, Hispanic Institute in the United States.

PODOL, Peter L. 1982. "Ritual and Ceremony in Luis Riaza's Theater of the Grotesque", Estreno 8.1, pp. 7-8, 17. 
PORQUERAS MAYO, Alberto. 1972. "Sobre el concepto vulgo en la Edad de Oro", en Temas y formas de la literatura española, Madrid, Gredos, pp. 114-127.

RAMOS, Alicia. 1982. "Luis Riaza: El dramaturgo y su obra", Entrevista con Luis Riaza, Estreno 8.1, pp. 18-21.

RIAZA, Luis. 1978. El desván de los machos y el sótano de las hembras, ed. Alberto Castilla y Luis Riaza, Madrid, Cátedra.

- 1981. Medea es un buen chico, Pipirijaina 18, pág. 8.

- 1977. Retrato de dama con perrito, Madrid, Editorial Fundamentos.

ROJAS, Fernando de. 1987. La Celestina, ed. Dorothy S. Severin, Madrid, Cátedra, pp. 95-96.

RUIZ PÉREZ, Pedro. 1986-87. "Teatro y metateatro en la dramaturgia de Luis Riaza", Anales de Literatura Española (Universidad de Alicante) 5.

RUIZ RAMÓN, Francisco. 1986. Historia del teatro español. Siglo XX $7^{\mathrm{a}}$ ed., Madrid, Cátedra.

SAINT EXUPÉRY, Antoine de. 1948. Citadelle, París, Gallimard.

- 1943. Le Petit Prince, New York, Reyanl \& Hitchock.

TRENAS, Julio. 1971. “El desván de los machos y el sótano de las hembras”, Arriba ,12 Noviembre.

URRUTIA, Jorge. 1985. "Actante y personaje (Los actantes)", El personaje dramático, Ponencias y debates de las VII jornada de teatro clásico español (1983), Madrid, Taurus, pp. 87-95. 